\title{
Student Nurses' Perception about Nursing Profession: A Comparative Approach
}

\section{Anil Kumar ${ }^{1}$, Sumandeep Kaur ${ }^{2}$, Harjeet Singh $^{3}$, Gurpreet Kaur ${ }^{4}$, Neelam Rani ${ }^{5}$, Diksha $^{6}$, Gaganpreet Kaur ${ }^{7}$, Gopika ${ }^{8}$, Gurmilanjot Kaur', Harman Kaur ${ }^{10}$, Bhupinderpal Kaur ${ }^{11}$, Harmanjot Kaur ${ }^{12}$}

${ }^{1}$ Associate Professor, University College of Nursing, Faridkot, Punjab, India.

${ }^{2}$ Tutor, University College of Nursing, Faridkot, Punjab, India

${ }^{3-12}$ Nursing students, University College of Nursing, Faridkot, Punjab, India

Corresponding Author: Sumandeep Kaur

\begin{abstract}
Background: Perception is a belief or opinion of people to interpret things. Perception plays a key role in molding the shape of an individual as a person and as a professional. As perception affects the working capacity of nurses, it is imperative to know about the current trends of perceived image of profession among future professionals.
\end{abstract}

Methods: A quantitative comparative study was conducted involving 200 student nurses in order to assess and compare the perceived image of the nursing profession among freshers (B.Sc. nursing first year students) and outgoing batches (B.Sc. Nursing final year students), using convenient sampling technique. The study was conducted in both selected public and private institutions located within the Faridkot district of Punjab state. A five-point self- structured Likert scale was used to collect data from study subjects. Data was collected using the online mode via Google forms after written informed consent from participants.

Results: Perceived image of nursing profession was significantly more positive $(\mathrm{p}=0.026)$ among freshers when compared with final year students. A highly significant association $(p=0.000)$ was found in the perceived image of the nursing profession with the type of institution. Student nurses from private institutions had significantly higher positive perception about the profession. Most of the final year students felt that nurses don't get due respect in the society.

Conclusion: It is concluded that first year nursing students were more positive and enthusiastic about the nursing profession as compared to the outgoing batches. Students from government institutions had a drastically less favorable perceived image of the nursing profession in comparison to those studying in private institutions.

Keywords: Nursing Profession, Perception, Undergraduate students, Freshers

\section{INTRODUCTION}

Nursing is a noble profession. From the early era, it has been considered a symbol of affection and dedication. The role of the nurse has gradually changed from that of a mother to one with a much broader scope. Nursing is now a profession which requires skills, expertise and knowledge; and which aims to provide a comprehensive care to an individual. ${ }^{[1,2]}$

For a profession to build up and grow, it requires strong will power and positive attitude of its personnel. Most indispensable criteria for any person joining a profession are having a strong passion and influential ideas regarding that profession. Whenever a person thinks of joining a particular profession, he/she has personal perspectives, views and understanding of it, which helps in molding the shape of an individual as a person and as a professional. ${ }^{[3]}$ Positive image of nursing as a profession is vital for successful recruitment and retention of nursing staff. ${ }^{[4]}$ 
By assessing and comparing the perceived image of the nursing profession among first year and final year students, researchers were trying to explore how the perception of students towards nursing profession changes with passage of time. An understanding of students' perception and its evolution during the course of the study can assist nurse educators in evaluating the educational program and be helpful in upliftment of profession by making requisite modifications and renovations.

\section{MATERIAL AND METHODS}

This study was conducted over a period of two months (June 2020 to July 2020), in selected public and private institutions situated within the Faridkot district of Punjab State. Study draft was approved by the institutional ethical committee, and the approval of the principals of concerned colleges was taken before conducting the study. A sociodemographic tool and self-structured fivepoint Likert scale was developed by authors in order to assess the perceived image of the nursing profession, which was approved by a group of experts. Data collected from the pilot study was used to check the reliability of the tool and the coefficient of reliability was found to be, $r=0.823$ by using split half method.

There were a total 10 items in the five-point Likert scale. For positive statements the scoring was 5-1 from strongly agree to strongly disagree and for negative statements 1-5 from strongly agree to strongly disagree. The total score was categorized into 3 categories having equal interval width (table 1).

Table 1: Likert Scale Scoring

\begin{tabular}{|l|l|l|}
\hline \multicolumn{3}{|c|}{ Table 1: Likert Scale Scoring } \\
\hline 1. & $10-23$ & Equivalent Category \\
\hline 2. & $24-36$ & Negative Perceived Image \\
\hline 3. & $37-50$ & Neutral Perceived Image \\
\hline
\end{tabular}

A quantitative comparative approach was used for this study. The study population comprised of B.Sc. Nursing first year and B.Sc. Nursing final year students of selected nursing colleges. In the wake of Covid-19 pandemic to minimize physical interactions, data were collected using online mode. A written informed consent was taken from all the study subjects after sharing complete information about the study. Average time taken by an individual study subject to complete the tool was 5-10 minutes. Response was limited to once for an individual subject. Confidentiality of subjects was maintained. Data were collected from 200 subjects, 100 each from B.Sc. Nursing $1^{\text {st }}$ year and B.Sc. Nursing 4th year by using convenient sampling technique. Responses were obtained in Google drive of the researcher to maintain confidentiality of data.

\section{STATISTICAL ANALYSIS:}

The data collected through online mode were organized and coded in Microsoft Excel. Objective wise analysis was done using SPSS (SPSS software, version 23, SPSS Inc. Chicago) software. Comparison of perception scores was done using the 't' test. Chi Square test was used to find out association between perceived image of nursing profession and demographic variables. Results were presented in the form of means, frequencies and percentages. A ' $\mathrm{p}$ ' value of $<.05$ was taken as statistically significant.

\section{RESULTS}

Out of total 200 subjects, 100 were from B.Sc. Nursing first year and the other 100 were from final year. $84.5 \%$ were females, whereas $15.5 \%$ were males. $58.5 \%$ were studying in government institutions while $41.5 \%$ were studying in private institutions (table 2).

The mean scores on Likert scale related to perception of nursing profession are shown in table 3. The score of B.Sc. Nursing first year is significantly higher as compared to final year students. This comparison done using the ' $\mathrm{t}$ ' test yields a p-value of 0.026 , as depicted in table 3 . 
Table 2: Frequency and percentage distribution of demographic characteristics of study subjects, $\mathrm{N}=200$

\begin{tabular}{|c|c|c|}
\hline \multirow{2}{*}{$\begin{array}{l}\text { Demographic } \\
\text { Variables }\end{array}$} & First Year Students, $\mathbf{N}=100$ & Final Year Students, $\mathrm{N}=100$ \\
\hline & Frequency and \%age & Frequency and \%age \\
\hline \multicolumn{3}{|l|}{ Age } \\
\hline Less than 18 & $3(3 \%)$ & $0(0 \%)$ \\
\hline $18-20$ & $87(87 \%)$ & $4(4 \%)$ \\
\hline More than 20 & $10(10 \%)$ & $96(96 \%)$ \\
\hline \multicolumn{3}{|l|}{ Gender } \\
\hline Male & $20(20 \%)$ & $11(11 \%)$ \\
\hline Female & $80(80 \%)$ & $89(89 \%)$ \\
\hline \multicolumn{3}{|l|}{ Religion } \\
\hline Sikhism & $69(69 \%)$ & $77(77 \%)$ \\
\hline Hinduism & $25(25 \%)$ & $20(20 \%)$ \\
\hline Christianity & $2(2 \%)$ & $2(2 \%)$ \\
\hline Islam & $4(4 \%)$ & $1(1 \%)$ \\
\hline \multicolumn{3}{|l|}{ Area of residence } \\
\hline Urban & $44(44 \%)$ & $42(42 \%)$ \\
\hline Rural & $56(56 \%)$ & $58(58 \%)$ \\
\hline \multicolumn{3}{|c|}{ Monthly family income (in INR) } \\
\hline Less than 10000 & $26(26 \%)$ & $20(20 \%)$ \\
\hline $10001-20000$ & $32(32 \%)$ & $23(23 \%)$ \\
\hline $20000-30000$ & $16(16 \%)$ & $19(19 \%)$ \\
\hline More than 30000 & $26(26 \%)$ & $38(38 \%)$ \\
\hline \multicolumn{3}{|c|}{ Type of institution } \\
\hline Government & $59(59 \%)$ & $58(58 \%)$ \\
\hline Private & $41(41 \%)$ & $42(42 \%)$ \\
\hline \multicolumn{3}{|c|}{ Any family member/relative in Nursing profession } \\
\hline Yes & $39(39 \%)$ & $46(46 \%)$ \\
\hline No & $61(61 \%)$ & $54(54 \%)$ \\
\hline
\end{tabular}

Table 3: Mean, Standard Deviation and comparison of perceived image of nursing profession among study subjects.

\begin{tabular}{|l|l|l|l|}
\hline Year of Course & Mean \pm SD & t-test & p-value \\
\hline B.Sc. Nursing 1st year & $39.19 \pm 4.962$ & 2.237, Df $=198$ & 0.026 \\
\cline { 1 - 2 } B.Sc. Nursing Final year & $37.48 \pm 5.186$ & & \\
\hline
\end{tabular}

A sub-analysis was done to find how the students felt about the perception of nursing profession in the civil society. It was found that mean score related to this question was lower in final year students as compared to first year students (2.34 \pm $1.148,2.87 \pm 1.236$; $\mathrm{p}=0.002$ ).

The differences in the perception about nursing profession among the subjects studying in government vs private institutions is shown in figure 1.

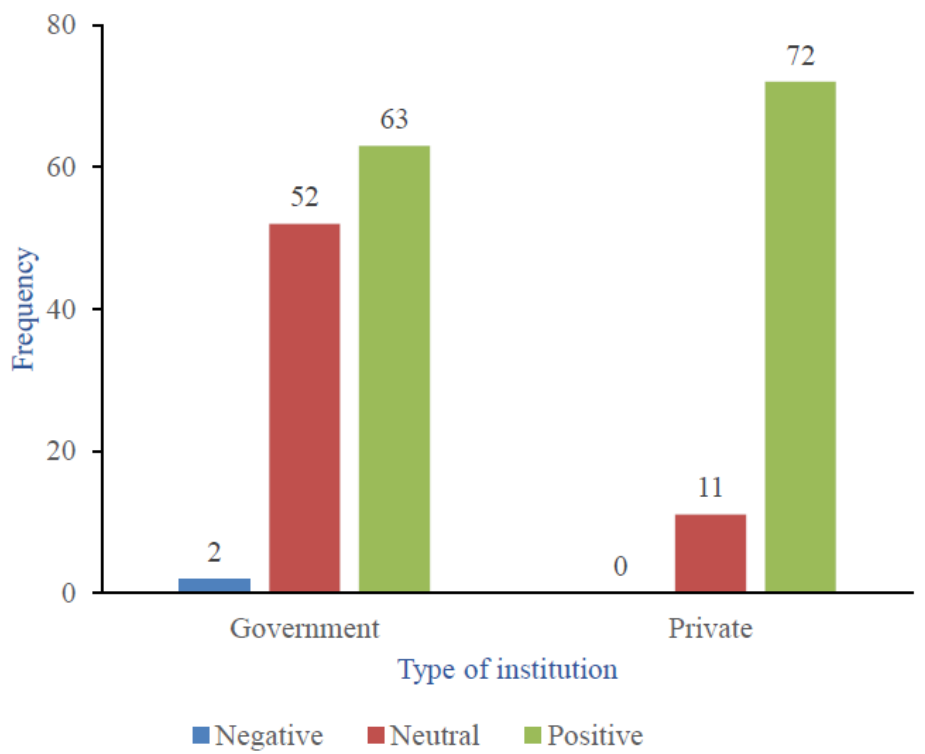

Figure 1: Representing association between perceived image of nursing profession among study subjects and type of institution. 
Students from private institutions had more positive perception as compared to those studying in government institutions $(p=.000)$. None of the subjects from private institution had negative perception while 2 subjects from government institutions had negative perception about nursing profession. Out of the total 63 subjects who had neutral perception only 11 belonged to private institutions. Sixty-three subjects from government institutions which accounts for $31.5 \%$ of total subjects had a positive perception in comparison to 72 subjects of private institutions which makes up $36 \%$ of total 200 subjects.

\section{DISCUSSION}

In our study, most students from first year i.e., $75 \%$ had positive perception; $24 \%$ had neutral and only $1 \%$ had negative perception about the nursing profession. While $60 \%$ from final year had positive perception, 39\% had neutral perception and only $1 \%$ had negative perception about their profession. This study is in accordance with the study conducted by Saffa R. Mahmoud, which revealed that $92.9 \%$ of studied subjects had a positive attitude about the nursing profession and $70.2 \%$ of them had a high level of study adjustment. ${ }^{[5]}$ A study by Abdel EL- Halem et al. on undergraduate male nurses disclosed that $62.16 \%$ of students had positive image of nursing profession. ${ }^{[6]}$ Another study conducted by Ashalata, Devi also concluded that majority of students (96.2\%) had good attitude and none of the students were having negative attitude towards the profession. ${ }^{[7]}$

A study conducted by Vijayalakshmi Poreddi et al. revealed that $48.8 \%$ of their study subjects agreed that social prejudice has a great influence nursing students in choosing nursing profession as their career, ${ }^{[8]}$ while our study results show that most of final year students perceive that nurses don't get due respect in society.

The present study has shown that nursing students become less positive about their profession as they progress from first year to final year. Most of the nursing students also think that they aren't getting due respect in society. It is the need of the hour that nursing institutes and our policy makers must take urgent actions to improve the image of nursing profession among professionals and public of the country.

\section{CONCLUSION}

Students of first year were significantly more positive and enthusiastic about their profession as compared to final year students. Subjects from government institutions had drastically less favorable perception about nursing when compared with subjects of private institutions. To sustain the positivity and enthusiastic perception of the first-year students up to final year, necessary steps must be taken by the management and faculty nursing institutions for continuous growth of the nursing profession.

\section{ACKNOWLEDGEMENTS}

Authors acknowledge the contribution of Principal and of all the faculty of University College of Nursing for their never-ending support and cooperation.

Funding: No funding source

Conflict of Interest: None declared

Ethical approval: The study was approved by the Institutional ethical committee.

\section{REFERENCES}

1. Kathreena MU, D'Silva JJ, Lobo JM et al. A study to assess the attitude towards nursing profession among the nursing students in selected colleges at Mangalore. Int J Health Sci Res. 2015; 5(10):217-220.

2. Cukljek S, Juresa V, Bile C, et al. Changes in nursing student's attitude towards nursing during undergraduate study. Acta clinica Croat. 2017; 56(1):36-43.

3. Swarna S. Nursing students Perception towards Profession and Future Intentions. IOSR Journal of Nursing and Health Science. 2015; 4(5):30-34.

4. Zulu C, Ngoma C. A survey on perception of the image of nursing profession in 
Zambia by nursing students at the department of Nursing sciences, University of Zambia. Unified Journals of Nursing and Midwifery. 2015;1(1):01-14.

5. Mahmoud SR, Abd-Elhafez KH, Marzouk SA, et al. Nursing students' Attitude towards Nursing Profession and its relation to Study adjustment. International Journal of Nursing Didactics 2019; 9(07):09-15.

6. Abdel El-Halem GE, El Hawashy Ul, Gamal El-Dein AA, et al. Undergraduate male Nursing student's perception about the image of Nursing Profession. Journal of American Science. 2011; 7 (3); 614-23.

7. Ashalata, Devi. A study to assess the knowledge and attitude of nursing students towards nursing profession among students of Manipal College of Medical Sciences, Pokhara, Koski District Nepal, International Journal of Nursing Care.2013;1(1):10-15.

8. Poreddi V, Ramachandra, Konduru R, et al. Assessing the attitude and perceptions towards the Nursing profession among Nursing students. Nursing Journal of India. 2012;103(1):6-8.

How to cite this article: Kumar A, Kaur S, Singh $\mathrm{H}$ et.al. Student nurses' perception about nursing profession: a comparative approach. International Journal of Science \& Healthcare Research. 2021; 6(3): 149-153. DOI: https:// doi.org/10.52403/ijshr.20210724 